\title{
Methodology for Measuring Conformation of Solvent-Disrupted Protein Subunits using T-WAVE Ion Mobility MS: An Investigation into Eukaryotic Initiation Factors
}

\author{
Julie A. Leary, ${ }^{a}$ Matthew R. Schenauer, ${ }^{a}$ Raluca Stefanescu, ${ }^{a}$ \\ Armann Andaya, ${ }^{a}$ Brandon T. Ruotolo, ${ }^{b}$ Carol V. Robinson, ${ }^{b}$ \\ Konstantinos Thalassinos, ${ }^{\mathrm{c}}$ James H. Scrivens, ${ }^{\mathrm{c}}$ Masaaki Sokabe, ${ }^{\mathrm{d}}$ and \\ John W. B. Hershey ${ }^{\mathrm{d}}$ \\ ${ }^{a}$ Department of Molecular and Cellular Biology, University of California at Davis, Davis, California, USA \\ ${ }^{\mathrm{b}}$ Department of Chemistry, University of Cambridge, Cambridge, United Kingdom \\ c Department of Biological Sciences, University of Warwick, Coventry, United Kingdom \\ d Department of Biochemistry and Molecular Medicine, School of Medicine, University of California at Davis, \\ Davis, California, USA
}

The methodology developed in the research presented herein makes use of chaotropic solvents to gently dissociate subunits from an intact macromolecular complex and subsequently allows for the measurement of collision cross section (CCS) for both the recombinant (R-eIF3k) and solvent dissociated form of the subunit (S-eIF3k). In this particular case, the $\mathrm{k}$ subunit from the eukaryotic initiation factor 3 (eIF3) was investigated in detail. Experimental and theoretical CCS values show both the recombinant and solvent disrupted forms of the protein to be essentially the same. The ultimate goal of the project is to structurally characterize all the binding partners of eIF3, determine which subunits interact directly, and investigate how subunits may change conformation when they form complexes with other proteins. Research presented herein is the first report showing retention of solution conformation of a protein as evidenced by CCS measurements of both recombinant and solvent disrupted versions of the same protein. (J Am Soc Mass Spectrom 2009, 20, 1699-1706) (c) 2009 Published by Elsevier Inc. on behalf of American Society for Mass Spectrometry

$\mathrm{T}$ The ability to measure the conformation of intact macromolecular complexes has long been the domain of electron microscopy. With the advent of the traveling-wave (T-WAVE) Synapt ion mobility mass spectrometer (IM-MS) [1-3], however, possibilities now exist for extracting both mass and collision cross section data for peptides, proteins, carbohydrates, and other biological molecules. Given the very dynamic nature of biology, the ability to easily retrieve conformational information and/or differences for these types of compounds is quite appealing.

A plethora of ion mobility data has been generated for small molecules, peptides, and small proteins using traditional static field, home built instruments [4-11]. Data collected for these compounds were obtained primarily from researchers and laboratories whose expertise is in the area of instrument development and fabrication, and thus the technology has not been available to a large audience of researchers. Only recently

Address reprint requests to Dr. J. A. Leary, Department of Molecular and Cellular Biology, University of California at Davis, 1 Shields Rd., Briggs 130, Davis, CA 95616, USA. E-mail: jaleary@ucdavis.edu has an ion mobility instrument capable of generating collision cross section data been made commercially available. As with any new development, extensive research and proof-of-principle is currently being produced to unambiguously show that data generated from this new geometry instrument is comparable to that generated from traditional static field instruments. Thus, detailed methodology using both standards and controls were used in this study to delineate the appropriate conditions that allow for accurate determination of cross section measurements for the $\mathrm{k}$ subunit derived from eIF3, an initiation factor involved in translation. Both the recombinant form of this subunit and the subunit that was solvent disrupted directly off the intact eIF3 complex, were analyzed. Given the importance of eIF3 in translation and the lack of detailed structural data about this complex and its interactions, IM-MS is likely to be the single most productive technique for its analysis.

The mammalian eukaryotic initiation factor 3 is a large protein complex that, together with other eIFs (at least 12 in total), orchestrates the initiation of translation in eukaryotic cells [12-14]. Initiation of protein synthe- 
sis in mammalian cells involves the $40 \mathrm{~S}$ ribosomal subunit binding $\mathrm{tRNA}_{\mathrm{i}}{ }^{\text {Met }}$ and mRNA, before the $60 \mathrm{~S}$ subunit binding, to form a competent initiation complex [15]. The eIF3 factor is the largest and most complex of the eIFs and is composed of 13 non-identical protein subunits. Of the 13 subunits, labeled a-m, many are subject to extensive post-translational modification [16]. Likewise, eIF3 interacts with at least five other eIFs as well as the $40 \mathrm{~S}$ ribosomal subunit preventing premature association with the $605[13,14]$. Given its large size, number of interaction partners, extensive level of posttranslational regulation, and the fact that several reactions of the initiation pathway are stimulated by eIF3, it is highly likely that eIF3 acts as a scaffold, coordinating many other players in the initiation process.

Despite its key role in translation initiation, only recently has eIF3 been submitted to detailed structural investigation. Results obtained from structural modeling and cryoelectron microscopy have localized eIF3 to the solvent accessible face of the $40 \mathrm{~S}$ subunit [17]. Initial studies by our groups have determined that the eIF3 complex is composed of 13 heterogenous subunits present in stoichiometric amounts. It was also inferred, based on gas-phase lability, that the subunits $k, m, i$, and $h$ might be localized to the periphery of the complex. While two MS-based studies from our groups have determined the multitude of post-translational modifications present on the eIF3 subunits, as well as their inter-subunit contacts when present in the intact particle [16, 18], this study presents new data on the theoretical and experimental collision cross sections of one of the subunits using methodology developed and adapted for use with T-WAVE IM-MS.

\section{Experimental}

\section{eIF3 Purification from HeLa Cell Extracts}

The purification of eIF3 has been previously reported [16]. Briefly, $400 \mathrm{~mL}$ ( $150 \mathrm{~g}$ cells) of HeLa cell lysate (gift provided by R. Tjien Laboratory) was quickly thawed in a $37^{\circ} \mathrm{C}$ water bath after which five protease tablets (Roche, Indianapolis, IN, USA) were dissolved in the lysate and the following were added: $10 \%$ glycerol, $1 \mathrm{mM}$ EDTA, $1 \mathrm{mM}$ EGTA, $50 \mathrm{mM} \mathrm{NaF}$, and 50 $\mathrm{mM} \beta$-glycerol phosphate. The mixture was centrifuged at $4{ }^{\circ} \mathrm{C}$ for $20 \mathrm{~min}$ at $20,000 \times g$. The supernatant was collected $(\sim 400 \mathrm{~mL})$, and to it $4 \mathrm{M} \mathrm{KCl}$ was added to a final concentration of $450 \mathrm{mM}$. The solution was again centrifuged at $44,000 \mathrm{rpm}$ for $4 \mathrm{~h}$ at $4{ }^{\circ} \mathrm{C}$. Supernatant was removed and to it $3.9 \mathrm{M}$ ammonium sulfate was added to yield a $40 \%$ solution. The solution was stirred for $1 \mathrm{~h}$ at $4^{\circ} \mathrm{C}$, after which time it was centrifuged for 20 min at $10,000 \times g$ at $4{ }^{\circ} \mathrm{C}$ to recover the pellet. The pellet was then resuspended in Buffer A consisting of $20 \mathrm{mM}$ HEPES, pH 7.5, 10\% glycerol, $1 \mathrm{mM}$ EDTA, $1 \mathrm{mM}$ EGTA, $50 \mathrm{mM} \mathrm{KCl}, 50 \mathrm{mM} \mathrm{NaF}, 50 \mathrm{mM} \beta$-glycerol phosphate, and $1 \mathrm{mM}$ DTT. The lysate solution was placed in a $10 \mathrm{kDa}$ MWCO dialysis cassette (Pierce
Biotechnology Inc., Rockford, IL, USA) and dialyzed against $2 \mathrm{~L}$ of Buffer A for $2.5 \mathrm{~h}$ at $4{ }^{\circ} \mathrm{C}$. After dialysis, the lysate was spun at $40,000 \times g$ for $30 \mathrm{~min}$ at $4{ }^{\circ} \mathrm{C}$, and the supernatant loaded onto a MonoQ $(10 / 10)$ column (GE Healthcare, Piscataway, NJ, USA), which had been previously equilibrated with Buffer A. Buffer B, which consists of $20 \mathrm{mM}$ HEPES, pH 7.5, 10\% glycerol, $1 \mathrm{M}$ $\mathrm{KCl}, 1 \mathrm{mM}$ EDTA, $1 \mathrm{mM}$ EGTA, $50 \mathrm{mM}$ NaF, $50 \mathrm{mM}$ $\beta \mathrm{GP}, 1 \mathrm{mM}$ DTT, was run through the column at a gradient of $10 \%-60 \%$ with a flow rate of $1.5 \mathrm{~mL} / \mathrm{min}$ with $3 \mathrm{~mL}$ fractions collected. Fractions containing eIF3 were identified via SDS-PAGE (Figure 1), pooled, and dialyzed against Buffer A for $2.5 \mathrm{~h}$ at $4{ }^{\circ} \mathrm{C}$. After dialysis, the lysate was loaded onto a MonoS (10/10) column (GE Healthcare) previously equilibrated in Buffer A. Fractions were then collected under the same conditions as that previously stated for the MonoQ $(10 / 10)$. Fractions containing eIF3 were then individually aliquoted and flash frozen in liquid nitrogen for future use. In two separate preparative procedures, the concentration of protein remaining after purification was found to be 2.8 (Stock A) and 12.5 (Stock B) $\mathrm{mg} / \mathrm{mL}$, respectively, by using Nanodrop UV analysis (NanoDrop Technologies, LLC, Wilmington, DE, USA).

\section{Expression and Purification of Recombinant eIF3k Subunit}

The cDNA encoding eIF3k in pET-Hisp28 [19] was digested with NDII and XhoI and cloned into a modified pET28c vector harboring $\mathrm{His}_{6} \mathrm{MBP}$ flanked by a TEV protease digestion site at the N-terminus of multicloning site. The $\mathrm{His}_{6}$-MBP fused eIF3k was expressed in E. coli BL21 (DE3) in LB medium containing 25 $\mathrm{mg} / \mathrm{mL}$ kanamycin at $37^{\circ} \mathrm{C}$. The cells were incubated to $\mathrm{OD}_{600} 0.6,0.5 \mathrm{mM}$ IPTG was added, the incubation was continued for $4 \mathrm{~h}$, and cell were harvested and stored at $70^{\circ} \mathrm{C}$. Cells were disrupted by sonication in

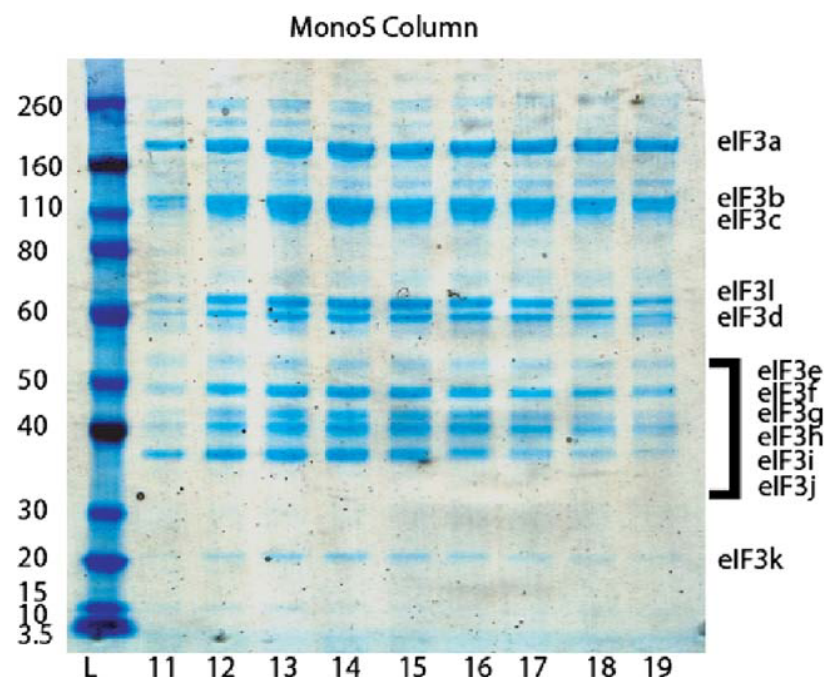

Figure 1. Gel fractions indicating presence of each of the eIf3 subunits. 
Buffer A (20 mM Tris- $\mathrm{HCl} \mathrm{pH} 7.5,0.4 \mathrm{M} \mathrm{KCl}$, and $5 \mathrm{mM}$ $\beta$-mercaptoethanol). The extract was applied to HisTrap 5 $\mathrm{mL}$ column (GE Healthcare) equilibrated with Buffer A, washed with Buffer A containing $25 \mathrm{mM}$ imidazole, and then eluted with Buffer A containing $250 \mathrm{mM}$ imidazole. The eluate was subjected to TEV digestion for $17 \mathrm{~h}$ during dialysis against Buffer B (20 mM HEPES-K pH 7.5, $50 \mathrm{mM} \mathrm{KCl}, 5 \mathrm{mM}$ mercaptoethanol), and then was reapplied to the HisTrap $5 \mathrm{~mL}$ column equilibrated with Buffer B. The flow-through was collected and applied to a Mono Q 5/5 column (GE Healthcare) equilibrated with Buffer B, and eluted with a 50 to 500 $\mathrm{mM}$ linear $\mathrm{KCl}$ gradient in Buffer $\mathrm{B}$. The buffer was exchanged to $20 \mathrm{mM}$ HEPES-K pH 7.5, $200 \mathrm{mM}$ ammonium acetate, and $1 \mathrm{mM}$ DTT by using an Amicon Ultra molecular weight cut-off (MWCO) 10 kDa filter (Millipore, Bedford, MA, USA). The protein was concentrated to $14 \mathrm{mg} / \mathrm{mL}$, flash frozen with liquid nitrogen, and stored at $-70{ }^{\circ} \mathrm{C}$. The procedure yields a protein after TEV digestion with four additional amino acids (GHMA) before the first methionine of eIF3k.

\section{Sample Preparation for MS}

Bovine carbonic anhydrase II was purchased from Sigma-Aldrich (St. Louis, MO, USA). For IM-MS analysis the sample was buffer exchanged to $10 \mathrm{mM}$ ammonium acetate, $1 \mathrm{mM}$ DTT using the Micro Bio-Spin Chromatography columns packed with Bio-Gel P-6 polyacrylamide gel matrix manufactured by Bio-Rad (Hercules, CA, USA). Before mass spectrometric analysis the sample was diluted to a final concentration of 10 micromolar. Solutions for analysis were delivered by nanospray tips made in-house.

Forty microliters of purified eIF3 was buffer-exchanged successively two to four times using Bio-Rad Micro Bio-Spin chromatography columns (Bio-Rad). The columns were pre-equilibrated with a buffer containing 100-200 mM NH${ }_{4} \mathrm{OAc}$ and $1 \mathrm{mM}$ DTT. A solution of 10 $\mu \mathrm{g} / \mu \mathrm{L}$ bovine serum albumin (BSA) was then rinsed over the columns to block any nonspecific protein binding sites. The BSA solution was subsequently removed from the columns leaving each equilibrated with the buffer ready for sample loading. After buffer exchange, the intact eIF3 was partially disrupted via addition of $20 \%$ (vol/vol) dimethylformamide (DMF) or TFE. Recombinant eIF3k (R-eIF3k) was prepared in a similar fashion, but without addition of DMF or TFE.

\section{Ion Mobility Parameters}

A Synapt HDMS (Waters Corp., Milford, MA, USA) mass spectrometer was used for all analyses. This instrument incorporates a traveling wave ion mobility separation device between the quadrupole and time-offlight (TOF) analyzer in a qTOF mass spectrometer. Specific information on geometry of this instrument has been published by Pringle et al. [2].
Bovine carbonic anhydrase II (BCA) was used as a general model protein to check experimental collision cross sections (CCS) with theoretically obtained values. For these experiments, the instrument was operated in the positive ion mode with a capillary voltage of $0.8 \mathrm{kV}$, $25 \mathrm{~V}$ cone voltage, $13 \mathrm{~V}$ bias, and $40^{\circ} \mathrm{C}$ source temperature. To preserve native protein conformation the source pressure was set to $\sim 6$ mbar with a $5 \mathrm{~V}$ trap collision energy (CE). Measurements were taken at 0.50 mbar pressure in the ion mobility cell at a $\mathrm{N}_{2}$ flow of 24 $\mathrm{mL} / \mathrm{min}$ and an Argon flow of $1.3 \mathrm{~mL} / \mathrm{min}$ in the trap and transfer region corresponding to a pressure of $2.0 \times$ $10^{-2} \mathrm{mBar}$. The traveling wave speed was maintained constant at $250 \mathrm{~m} / \mathrm{s}$, while IM-MS spectra were recorded at the wave height of 7.0 (University of California, Davis) and 9.0 (University of Warwick).

The R-eIF3k and the S-eIF3k proteins were run in a similar fashion, although some of the tuning parameters were set to slightly different values to maximize signal intensity and ion distribution across the bin width. In all cases, the sample and calibrants were run under identical conditions.

\section{Collision Cross Section Measurements}

Ion mobility arrival time distributions were converted to collision cross sections via calibration against the collision cross sections of myoglobin, cytochrome $c$ and ubiquitin as published previously [20, 21]. Briefly, the arrival time of each peak was first measured in scans. The scans were then converted to arrival time by multiplying by the pusher frequency. T-WAVE offsets from both the IM-MS and transfer regions were subtracted from the measured drift times. Subsequently, the drift times were further corrected to account for $\mathrm{m} / \mathrm{z}$ dependent flight times on exit from the T-WAVE region and in the TOF analyzer using estimates based on the flight time of a $1000 \mathrm{~m} / \mathrm{z}$ ion. These corrected arrival times are the analytically useful quantities for both the calibrant ions and the analyte. The published cross sections were then corrected to reflect the reduced mass of the ion-neutral pair and charge state. The corrected cross sections were plotted against the corrected drift times using a power series which provides an appropriate fit (Figure 2). Using the regression equation and the corrected drift times of the analyte ions, the calibrated collision cross sections for the species of interest were obtained. In the data presented here, charge states of myoglobin, cytochrome $c$, and ubiquitin were used as calibrant ions. Cross sections of the calibrants (corrected for reduced mass and charge) correlated well with corrected arrival times, and the data fit well to power series generally with a $\mathrm{R}^{2}$ values between 0.98 and 0.99 .

\section{Theoretical Calculations}

Collision cross-section (CCS) estimates were computed using a modified version of MOBCAL [22, 23] that omits the trajectory method (TJ) calculation, increases 


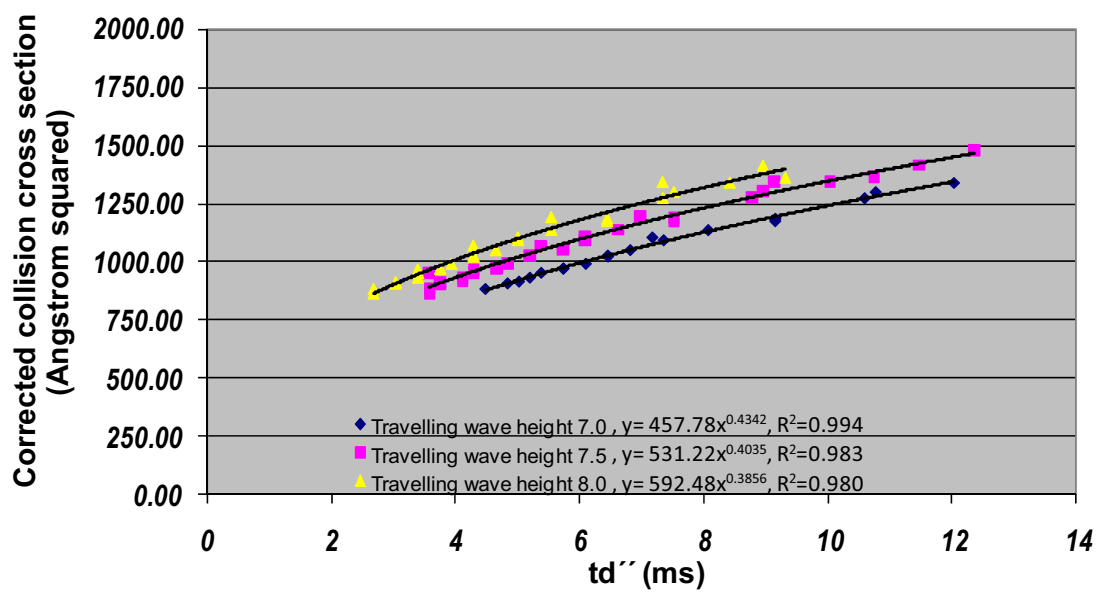

Figure 2. Calibration plots used for calculating the collision cross section of carbonic anhydrase. The plots were constructed based on the corrected collision cross section of published data and the experimental arrival times of the molecular ions of ubiquitin, cytochrome $c$ and myoglobin. IM-MS data were recorded at three wave heights and the data points corresponding to each wave height are displayed with (a) open diamond 7.0 V, (b) open square $7.5 \mathrm{~V}$, and (c) open triangle $8.0 \mathrm{~V}$.

the number of iterative calculations performed per input structure, and is capable of accepting input coordinate files that contain up to 100,000 atoms [24]. The crystal structure of eIF3 subunit k (pdb ID: 1rz4) was used as input for the calculations and was prepared only by removing all crystallographic water molecules from the structure. No hydrogen was added to the crystal structure before calculations, as previous experiments (data not shown) have indicated a negligible difference between CCS estimates achieved with their addition. Output is reported from both the projection approximation (PA) and exact hard sphere scattering (EHSS) methods within MOBCAL.

\section{Results and Discussion}

The goal of the study presented herein was to determine if the eIF3 subunits could be successfully separated under conditions gentle enough to retain secondary/ tertiary subunit structures using chaotropic solvents. The collision cross section (CCS) for one of the subunits, $\mathrm{k}$, was measured via IM-MS and compared with its recombinantly expressed form. General tuning parameters were also iteratively tested to gain insight into the calibration procedure as it relates to determining consistent collision cross section values. Given its proximity within the eIF3 complex, and the availability of a crystal structure with which to model theoretical cross sections for the folded protein, the eIF3k subunit was chosen to develop the general methodology.

The $\mathrm{k}$ subunit is the smallest protein of the eIF3 complex and has a molecular mass of $24,971 \mathrm{Da}$. It is conserved in various mammals, insects and plants and has been shown to reside on the periphery of the intact complex [18]. The structure of the $\mathrm{k}$ subunit also contains considerable helical content; i.e., $14 \alpha$ helices and two 3,10 helices, and portrays two general domains
[25]. Crystal structure coordinates available in the Protein Data Bank allowed for theoretical CCS calculations through MOBCAL [22, 23].

To accurately measure and compare the CCS of both the R-eIF3k and the S-eIF3k subunit, bovine carbonic anhydrase II (BCA) was used to establish accurate methodology and acquisition parameters. The molecular mass of BCA $(29,114 \mathrm{Da})$ approximates that of the $\mathrm{k}$ subunit and crystal structure coordinates are also available through the Protein Data Bank thus making it an appropriate control sample for comparison with the $k$ subunit. The CCS data for BCA is provided in Figure 3 and the accompanying Table 1. (A spectrum of BCA in

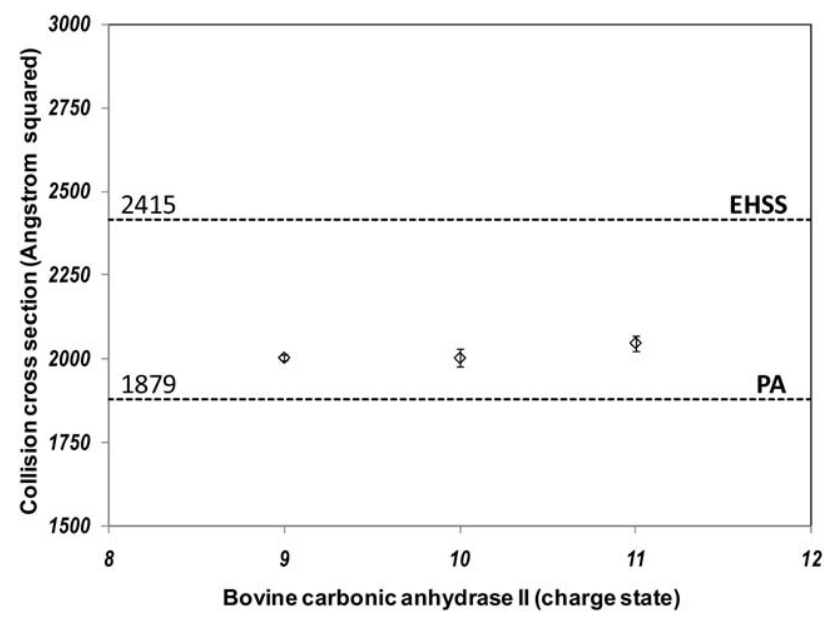

Figure 3. Comparison of the experimentally determined collision cross sections of bovine carbonic anhydrase II with the theoretical values. The values calculated from the arrival time distributions of the $9+, 10+$, and $11+$ molecular ions at a wave height of $7.0 \mathrm{~V}$ and are from 3 replicate samples. The values calculated using the exact hard-spheres scattering model (EHSS) and the projection approximation (PA) models using the crystal structure data available are indicated by dotted lines. 
Table 1. Collision cross section of bovine carbonic anhydrase II at the traveling wave height 7.0

\begin{tabular}{cccccrr}
\hline Charge state & Data set 1 & Data set 2 & Data set 3 & Average $\left(\AA^{2}\right)$ & St.Dev $\left(\AA^{2}\right)$ & St.Dev $(\%)$ \\
\hline \hline 9 & 1995.08 & 2005.53 & 2011.68 & 2004.10 & 8.38 & 0.41 \\
10 & 1994.70 & 1993.25 & 2022.26 & 2003.40 & 26.34 & 0.81 \\
11 & 2069.25 & 2022.78 & 2052.14 & 2048.06 & 23.50 & 1.14 \\
\hline
\end{tabular}

ammonium acetate is provided in the supplementary material, which can be found in the electronic version of this article).

Ionization of BCA, dissolved in ammonium acetate and electrosprayed under gentle conditions, produced three charge states, $9+, 10+$, and $11+$. In one set of experiments, ion mobility measurements were collected, in triplicate, at a wave height of 7.0 and the resulting data shown in Table 1 . In this set of experiments, tuning parameters were first optimized for the calibration compounds and then the sample data collected under identical conditions. As can be observed from the data, CCS values, for the lowest charge state of 9+, fall within the range of 1995 and $2011 \AA^{2}$, both of which are within the theoretical range of 1879 and 2415 $\mathrm{A}^{2 \mathrm{O}}$, for the PA (projection approximation) and EHSS (exact hard-spheres scattering) methods, respectively. The values for the $11+$ charge state data are somewhat higher, but this is not surprising given the observations that proteins begin to unfold as the charge state increases [26-29]. Most interesting is the fact that the lowest charge state measured, and the charge state most likely to resemble the solution conformation, gave similar results when measured on two different instruments by two different groups (see below). Based on these data, the average CCS value for the lowest $9+$ charge state was calculated to be $2004 \AA^{2}$.

In a second set of experiments collected on a different instrument by another member of the research team at another location (University of Warwick), the CCS measurements were made at one preselected wave height of 9.0. In this case, optimal wave height was determined by ensuring that the total arrival time distribution, for all ions in the mass spectrum, was spread across the most number of bins (200 in total) while not causing any "roll-over" effects. Calibration using the three standard compounds was then collected under identical conditions as those used to collect the BCA data. These experiments produced a CCS for the $9+$ charge state of $2041 \mathrm{~A}^{2 \mathrm{o}}$, and falls within the theoretical PA and EHSS values. The data are also quite close to the value obtained at the University of California, Davis location. These data support the premise that collision cross sections can be measured to within theoretical values using the T-WAVE system of mobility and provides a template from which to measure the cross sections of both a recombinant and a mammalian cell protein for comparative purposes. Regardless of the exact tuning paramenters, both experiments provided comparable values that were within theory providing each batch of sample and calibrants were run under identical conditions, even when collected at two independent laboratories.

Figure 4 is the mass spectrum of the eIF3 complex. At $150 \mathrm{~V}$ trap $\mathrm{CE}$, the two most peripheral subunits, $\mathrm{k}$ and $\mathrm{m}$, are dissociated from the complex and observed at the lower mass to charge ratio of the spectrum. The ion representative of the intact complex is observed at $\mathrm{m} / \mathrm{z}$ 14,500 , which deconvolutes to a molecular mass of 795,581 ( $\pm 56 \mathrm{Da}$ ) and is $\sim 458 \mathrm{Da}$ higher than the theoretical mass given the known molecular weights of each subunit and the number of post translationally modified phosphorylations determined previously [16]. This higher mass discrepancy is likely due to two possibilities: (1) solvent that remains associated with the complex under the gentle spray conditions used, and (2) additional phosphorylations that may have been undetected in the previous study [16]. Trap CE voltages can be varied to produce more or less of the $\mathrm{k}$ subunit while still retaining significant abundance of the intact complex (data not shown). A spectrum showing the DMF dissociated complex is provided in supplementary materials.

Having established that the eIF3 subunit stoichiometry was correct and with IMS tuning parameters verified for BCA, ion mobility measurements were subsequently measured for the recombinant form of the eIF3k subunit, and for the $\mathrm{k}$ subunit that was disrupted from the intact complex, using two different chaotropic solvents. In one case, trifluoroethanol (TFE), known to preserve helical structure, was used [30,31]. The second set of experiments was run using dimethyl formamide (DMF) to gently remove the $\mathrm{k}$ subunit from the intact complex. Collision cross section data for all four exper-

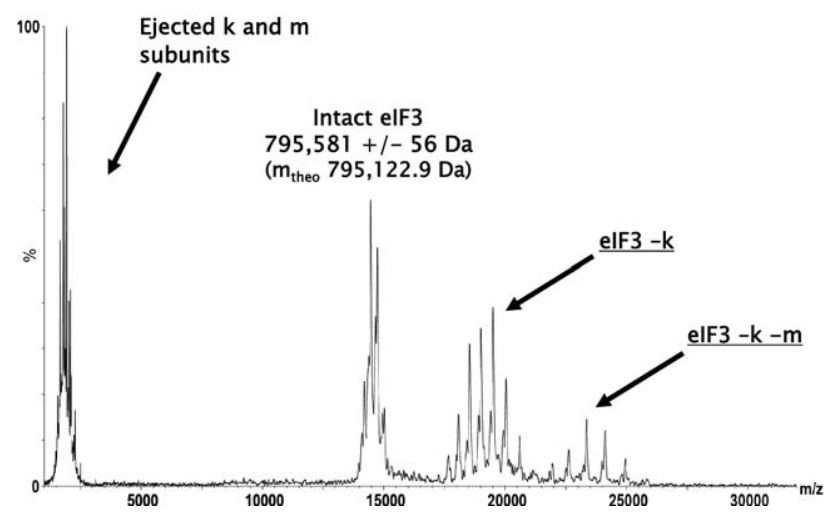

Figure 4. Mass spectrum of the eIF3 complex showing dissociation of subunits with accompanying charge stripped complementary ion distributions. The charge state distribution for the intact complex correspond to $56-53$ positive charges. 
iments are provided in Table 2, along with the PA and EHSS values calculated using MOBCAL. Both the S-eIF3k and recombinant R-eIF3k subunit arrival time distributions (ATDs) were converted to collision cross sections after calibrating the ATDs with the CCS of standard proteins (see the Experimental section). Cross sections for the $8^{+}$charge state of all the $\mathrm{k}$ subunit measurements fall within theoretically predicted values from the crystal structure using EHSS and PA methods. The cross section of the $8^{+}$charge state of R-eIF3K (sprayed in the absence of DMF) mirrors that of the TFE and DMF-dissociated protein, again indicating that, for this particular protein complex, the chaotropes used have not significantly perturbed the structure. The CCS values measured are in fact within $2 \%$; however, care must be taken in interpreting these values as they provide a relative comparison to each other, not an absolute value. At this time, it is well understood that non-static ion mobility cells can not provide absolute CCS.

Figures 5 and 6 are the arrival time distributions generated for the $9+$ and $8+$ charge states of the R-eIF3k and DMF disrupted S-eIF3k subunit, respectively, using different trap voltages. Apparent from both figures is the observation that increasing the trap voltage leads to unfolding of the protein, regardless of whether the complex is solvent dissociated from the complex, or present as the recombinant form. While the $9+$ charge state indicates unfolding at the lowest trap $\mathrm{CE}$, the $8+$ charge state data suggests only one conformation at both 5 and $10 \mathrm{~V}$. At the highest trap voltage for the $9+$ charge state, the initial conformation changes to one with a more elongated structure. The $8+$ complex, however, retains some of the original compact features while giving way to a more elongated structure as well. It is also clear from the data that the ATDs for both the recombinant and DMF-dissociated 8+ charge state of the $k$ subunit are the same and both CCS values for this charge state are within the theoretical PA and EHSS values calculated.

The data collected for both the R-eIF3k and the S-eIF3k proteins reveal several important features. The first obvious trend is that each of the measured CCS, for the lowest charge state, is within the PA and EHSS

Table 2. Experimental and theoretical collision cross sections determined for the $8+$ charge state of the recombinant and solvent dissociated eIF3k

\begin{tabular}{|c|c|c|c|c|c|}
\hline \multicolumn{4}{|c|}{ Experimentally measured cross sections } & \multirow{2}{*}{\multicolumn{2}{|c|}{$\begin{array}{c}\text { Theoretical } \\
\text { values }\end{array}$}} \\
\hline \multirow{2}{*}{$\begin{array}{l}\text { elF3k DMF } \\
\text { disrupted } \\
\qquad\left(\AA^{2}\right)^{+}\end{array}$} & \multirow{2}{*}{$\begin{array}{l}\text { elF3k TFE } \\
\text { disrupted } \\
\qquad\left(\AA^{2}\right)^{\dagger}\end{array}$} & \multirow{2}{*}{$\begin{array}{c}\text { relF3k in } \\
\mathrm{NH}_{4} \mathrm{OAc} \\
\left(\AA^{2}\right)^{\dagger}\end{array}$} & \multirow{2}{*}{$\begin{array}{c}\text { relF3k in } \\
\mathrm{NH}_{4} \mathrm{OAc} \\
\left(\AA^{2}\right)^{*}\end{array}$} & & \\
\hline & & & & $\begin{array}{c}\text { EHSS } \\
\left(\AA^{2}\right)\end{array}$ & $\begin{array}{l}\mathrm{PA} \\
\left(\AA^{2}\right)\end{array}$ \\
\hline 2070 & 2047 & 2095 & 2055 & 2441 & 1902 \\
\hline
\end{tabular}

*Value measured at a traveling wave height of 7.0. Day to day variability over $1 \mathrm{wk}$ for four replicates of the DMF dissociated subunit indicate less than $2 \%$ relative standard deviation.

${ }^{\top}$ Value measured using ramped wave heights from 0 to $30 \mathrm{~V}$.

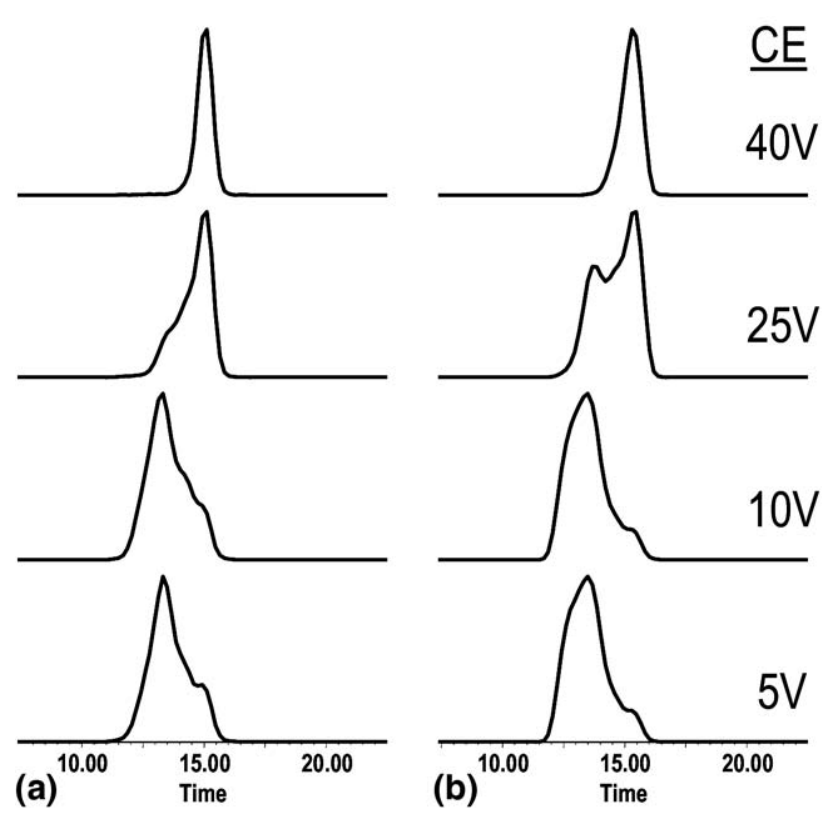

Figure 5. Arrival time profile of the $9+$ charge state of the solvent dissociated (a) and recombinant (b) eIF3k. IM-MS data, shown in milliseconds were acquired using ramped wave heights from 0 to $30 \mathrm{~V}$ and trap CE values varying from 5 to $40 \mathrm{~V}$.

theoretical values. Previous studies have shown that careful electrospraying of proteins in buffer preserve folded structures [32,33]. Whether all proteins remain properly folded or misfolded continues to be a debatable point, and is quite likely to depend on the tertiary structure of each individual protein studied. It has been shown, however, that under carefully controlled acquisi-

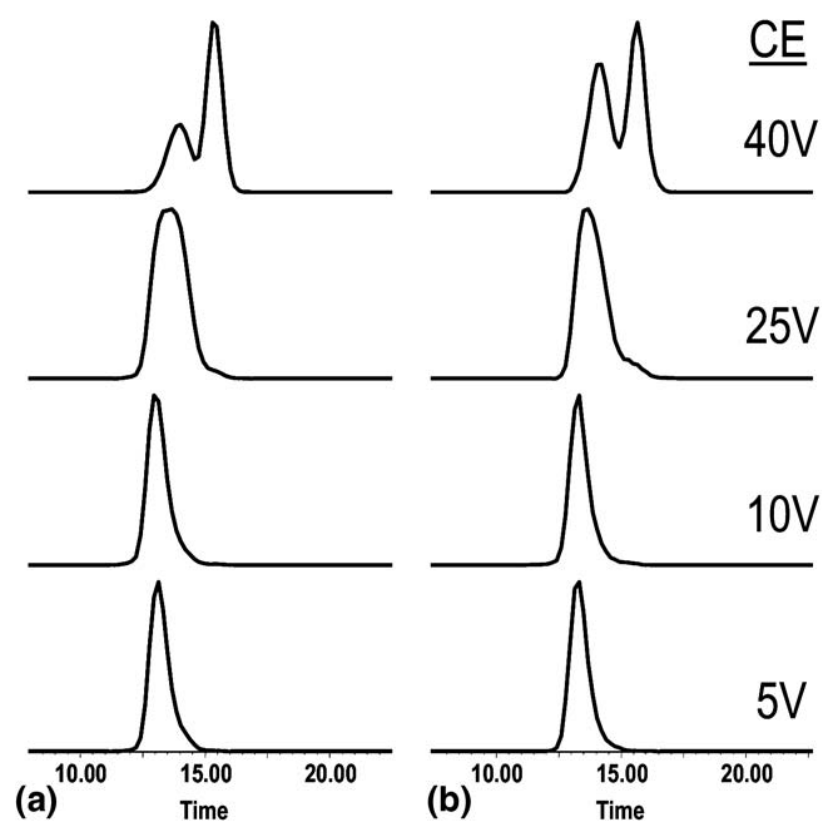

Figure 6. Arrival time profile of the $8+$ charge state of the solvent dissociated (a) and recombinant (b) eIF3k. IM-MS data, shown in milliseconds were acquired using ramped wave heights from 0 to $30 \mathrm{~V}$ and trap CE values varying from 5 to $40 \mathrm{~V}$. 
tion conditions the CCS of the lowest detected charge state will fall within the boundaries of the theoretically calculated values using the PA and EHSS methods of theory $[21,34]$. Thus the current method of analyzing the $\mathrm{k}$ subunit holds true to previous experiments.

The second important observation is that both the R-eIF3k and S-eIF3k subunits have approximately the same CCS. Since it is now known that the $\mathrm{k}$ subunit resides on the periphery of the intact complex [18] and has little or no interaction with the remaining complex in vitro, the current data in this study supports two important hypotheses: (1) chaotropic agents can be used to gently peel subunits from intact complexes with retention of conformation, and (2) gas-phase data generated in the T-WAVE system reflect the solution phase conformation for this protein isolated from mammalian cells. Chaotropic agents have been used previously for generating protein interaction maps $[35,36]$, but this is the first report showing that the CCS of a disrupted subunit from a complex is consistent with that of the recombinant form of the protein using mobility measurements. In this particular case, dissociation from the complex by use of the solvent does not appear to induce unfolding, rather complete dissociation occurs with minimal disruption of the protein subunit. This is strong support for using ion mobility to probe proteinprotein interactions in dynamic systems.

While the data are consistent with the theory, it is important to emphasize two important details. The first consideration to note is the importance of running the sample under identical conditions to that of the calibrant compounds. This is paramount and is underscored by the fact that the data for the two R-eIF3k samples shown in Table 2 were collected by different individuals using somewhat different tuning parameters, different wave heights and different calibration conditions. However, providing the sample and calibrant are collected under identical conditions, the data appear to be internally consistent. The second important issue is the realization that the boundaries of the PA and EHSS theoretical cross sections are quite broad; i.e., it is likely we can use this method for relative comparisons but rather dangerous to consider any measured value as absolute given the range of CCS between the two theoretical values. Advances in theory will need to be made to lessen the gap between the theoretical boundaries and in this regard new levels of theory are beginning to appear in the literature [37].

\section{Conclusions}

In conclusion, ion mobility mass spectrometry has been used to measure the stoichiometry of a heteromultimeric protein complex as well as to determine the collision cross section of one of the subunits that was gently dissociated from the complex using various chemical reagents. Cross sections determined for the dissociated protein are in good agreement with theory and match those of the recombinantly expressed pro- tein supporting retention of solution phase structure. At this time it is not known to what extent the T-WAVE system can be used to monitor minor changes in the secondary/tertiary structure and this is likely to vary from protein to protein. Agreement with current theoretical methods is, however, observable. As with any good analytical procedure, calibration and sample data should be collected under identical conditions and, as such, resulting cross sections for the sample are internally consistent.

\section{Acknowledgments}

J.A.L. and J.W.B.H. are grateful for funding from NIH PHS GM073732, which supports this research. B.T.R. is a Waters Research Fellow. C.V.R. is a Royal Society professor, and M.S. gratefully acknowledges his Human Frontier Science Program Fellowship (LT00575/2007). JAL is grateful to Dr. Iain Campuzano from Waters, Inc. for his helpful discussions and early assistance with the intact complex.

\section{Appendix A Supplementary Material}

Supplementary material associated with this article may be found in the online version at doi:10.1016/ j.jasms.2009.05.003.

\section{References}

1. Giles, K.; Pringle, S. D.; Worthington, K. R.; Little, D.; Wildgoose, J. L.; Bateman, R. H. Applications of a Traveling Wave-Based Radio-FrequencyOnly Stacked Ring Ion Guide. Rapid Commun. Mass Spectrom. 2004, 18(20), 2401-2414.

2. Pringle, S. D.; Giles, K.; Wildgoose, J. L.; Williams, J. P.; Slade, S. E.; Thalassinos, K.; Bateman, R. H.; Bowers, M. T.; Scrivens, J. H. An Investigation of the Mobility Separation of Some Peptide and Protein Ions Using a New Hybrid Quadrupole/Traveling Wave IMS/oa-ToF Instrument. Int. J. Mass Spectrom. 2007, 261(1), 1-12.

3. Ruotolo, B. T.; Giles, K.; Campuzano, I.; Sandercock, A. M.; Bateman R. H.; Robinson, C. V. Evidence for Macromolecular Protein Rings in the Absence of Bulk Water. Science 2005, 310(5754), 1658-1661.

4. Bohrer, B. C.; Merenbloom, S. I.; Koeniger, S. L.; Hilderbrand, A. E.; Clemmer, D. E. Biomolecule Analysis by Ion Mobility Spectrometry. Annu. Rev. Anal. Chem. 2008, 1(1), 293-327.

5. Kanu, A. B.; Dwivedi, P.; Tam, M.; Matz, L.; Hill, H. H. Jr. Ion Mobility-Mass Spectrometry. J. Mass Spectrom. 2008, 43(1), 1-22.

6. Verbeck, G. F.; Ruotolo, B. T.; Sawyer, H. A.; Gillig, K. J.; Russell, D. H. A Fundamental Introduction to Ion Mobility Mass Spectrometry Applied to the Analysis of Biomolecules. J. Biomol. Tech. 2002, 13(2), 56-61.

7. Wyttenbach, T.; Bowers, M. T. Topics in Current Chemistry, Gas-Phase Conformations: The Ion Mobility/Ion Chromatography Method, Modern Mass Spectromy 2003, 225, 207-232.

8. Koeniger, S. L.; Merenbloom, S. I.; Valentine, S. J.; Jarrold, M. F.; Udseth, H. R.; Smith, R. D.; Clemmer, D. E. An IMS-IMS Analogue of MS-MS. Anal. Chem. 2006, 78(12), 4161-4174.

9. Bernstein, S. L.; Wyttenbach, T.; Baumketner, A.; Shea, J. E.; Bitan, G.; Teplow, D. B.; Bowers, M. T. Amyloid $(\beta)$-Protein: Monomer Structure and Early Aggregation States of A $(\beta) 42$ and Its Pro19 Alloform. J. Am. Chem. Soc. 2005, 127(7), 2075-2084.

10. Tang, X.; Bruce, J. E.; Hill, H. H. J. Design and Performance of an Atmospheric Pressure Ion Mobility Fourier Transform Ion Cyclotron Resonance Mass Spectrometer. Rapid Commun. Mass Spectrom. 2007, 21(7), 1115-1122.

11. Fernandez-Lima, F. A.; Becker, C.; Gillig, K. J.; Russell, W. K.; Tichy, S. E.; Russell, D. H. Ion Mobility-Mass Spectrometer Interface for Collisional Activation of Mobility Separated Ions. Anal. Chem. 2009, 81(2), 618-624.

12. Hinnebusch, A. G. EIF3: A Versatile Scaffold for Translation Initiation Complexes. Trends Biochem. Sci. 2006, 31(10), 553-562.

13. Kapp, L. D.; Lorsch, J. R. The Molecular Mechanics of Eukaryotic Translation. Annu. Rev. Biochem. 2004, 73, 657-704.

14. Mathews, M. B.; Sonenberg, N.; Hershey, J. W. B. Cold Spring Harbor Monograph Series. New York, 2007 p. 1-895. 
15. Pestova, T. V.; Kolupaeva, V. G.; Lomakin, I. B.; Pilipenko, E. V.; Shatsky, I. N.; Agol, V. I.; Hellen, C. U. T. Molecular Mechanisms of Translation Initiation in Eukaryotes. Proc. Nat. Acad. Sci. U.S.A. 2001, 98(13), 7029-7036

16. Damoc, E.; Fraser, C. S.; Zhou, M.; Videler, H.; Mayeur, G. L.; Hershey, J. W. B. Doudna, J. A. Robinson, C. V. Leary, J. A. Structural Characterization of the Human Eukaryotic Initiation Factor 3 Protein Complex by Mass Spectrometry. Mol. Cell. Proteomics. 2007, 6(7), 1135-1146.

17. Siridechadilok, B.; Fraser, C. S.; Hall, R. J.; Doudna, J. A.; Nogales, E. Structural Roles for Human Translation Factor EIF3 in Initiation of Protein Synthesis. Science 2005, 310(5753), 1513-1515.

18. Zhou, M.; Sandercock, A. M.; Fraser, C. S.; Ridlova, G.; Stephens, E. Schenauer, M. R.; Yokoi-Fong, T.; Barsky, D.; Leary, J. A.; Hershey, J. W.; Doudna, J. A.; Robinson, C. V. Mass Spectrometry Reveals Modularity and a Complete Subunit Interaction Map of the Eukaryotic Translation Factor EIF3. Proc. Nat. Acad. Sci. U.S.A. 2008, 105(47), 18139-18144.

19. Mayeur, G. L.; Fraser, C. S.; Peiretti, F.; Block, K. L.; Hershey, J. W. Characterization of EIF3k-A Newly Discovered Subunit of Mammalian Translation Initiation Factor EIF3. Eur. J. Biochem. 2003, 270(20), 4133-4139.

20. Thalassinos, K.; Grabenauer, M.; Slade, S. E.; Hilton, G. R.; Bowers, M. T.; Scrivens, J. H. Characterization of Phosphorylated Peptides Using Traveling Wave-Based and Drift Cell Ion Mobility Mass Spectrometry. Anal. Chem. 2009, 81(1), 248-254.

21. Scarff, C. A.; Thalassinos, K.; Hilton, G. R.; Scrivens, J. H. Traveling Wave Ion Mobility Mass Spectrometry Studies of Protein Structure: Biological Significance and Comparison with X-Ray Crystallography and Nuclear Magnetic Resonance Spectroscopy Measurements. Rapid Commun. Mass Spectrom. 2008, 22(20), 3297-3304.

22. Mesleh, M. F.; Hunter, J. M.; Shvartsburg, A. A.; Schatz, G. C.; Jarrold, M. F. Structural Information From Ion Mobility Measurements: Effects of the Long-Range Potential. J. Phys. Chem. 1996, 100(40), 16082-16086.

23. Shvartsburg, A. A.; Jarrold, M. F. An Exact Hard-Spheres Scattering Model for the Mobilities of Polyatomic Ions. Chem. Phys. Lett. 1996, 261(1/2), 86-91

24. Ruotolo, B. T.; Benesch, J. L. P.; Sandercock, A. M.; Hyung, S.-J.; Robinson, C. V. Ion Mobility-Mass Spectrometry Analysis of Large Protein Complexes. Nat. Protoc. 2008, 3(7), 1139-1152.

25. Wei, Z.; Zhang, P.; Zhou, Z.; Cheng, Z.; Wan, M.; Gong, W. Crystal Structure of Human EIF3k, the First Structure of EIF3 Subunits. J. Biol. Chem. 2004, 279(33), 34983-34990.
26. Clemmer, D. E.; Jarrold, M. F. Ion Mobility Measurements and Their Applications to Clusters and Biomolecules. J. Mass Spectrom. 1997, 32(6), 577-592.

27. Koeniger, S. L.; Merenbloom, S. I.; Sevugarajan, S.; Clemmer, D. E. Transfer of Structural Elements from Compact to Extended States in Unsolvated Ubiquitin. J. Am. Chem. Soc. 2006, 128(35), 11713-11719.

28. Shelimov, K. B.; Clemmer, D. E.; Hudgins, R. R.; Jarrold, M. F. Protein Structure in Vacuo: Gas-Phase Confirmations of BPTI and Cytochrome c. J. Am. Chem. Soc. 1997, 119(9), 2240-2248.

29. Valentine, S. J.; Anderson, J. G.; Ellington, A. D.; Clemmer, D. E. Disulfide-Intact and -Reduced Lysozyme in the Gas Phase: Conformations and Pathways of Folding and Unfolding. J. Phys. Chem. B 1997, 101(19), 3891-3900

30. Luo, P.; Baldwin, R. L. Mechanism of Helix Induction by Trifluoroethanol: A Framework for Extrapolating the Helix-Forming Properties of Peptides from Trifluoroethanol/Water Mixtures Back to Water. Biochemistry 1997, 36(27), 8413-8421.

31. Pace, C. N.; Trevino, S.; Prabhakaran, E.; Scholtz, J. M. Protein Structure, Stability, and Solubility in Water and Other Solvents. Philos. Trans. R. Soc. Lond. B. Biol. Sci. 2004, 359(1448), 1225-1234.

32. Ganem, B.; Li, Y. T.; Henion, J. D. Detection of noncovalent receptorligand complexes by mass spectrometry. J. Am. Chem. Soc. 1991, 113(16), 6294-6296.

33. Katta, V.; Chait, B. T. Observation of the Heme-Globin Complex in Native Myoglobin by Electrospray-Ionization Mass Spectrometry. J. Am. Chem. Soc. 1991, 113(22), 8534-8535.

34. Scarff, C. A.; Patel, V. J.; Thalassinos, K.; Scrivens, J. H. Probing Hemoglobin Structure by Means of Traveling-Wave Ion Mobility Mass Spectrometry. J. Am. Soc. Mass Spectrom., 2009, 20(4), 625-631.

35. Hernandez, H.; Dziembowski, A.; Taverner, T.; Seraphin, B.; Robinson, C. V. Subunit Architecture of Multimeric Complexes Isolated Directly from Cells. EMBO. Reports 2006, 7(6), 605-610.

36. Hernandez, H.; Robinson, C. V. Determining the Stoichiometry and Interactions of Macromolecular Assemblies from Mass Spectrometry. Nat. Protoc. 2007, 2(3), 715-726.

37. Smith, D. P.; Knapman, T. W.; Campuzano, I.; Malham, R. W.; Berryman, J. T.; Radford, S. E.; Ashcroft, A. E. Deciphering Drift Time Measurements from Traveling Wave Ion Mobility Spectrometry-Mass Spectrometry Studies. Eur. J. Mass Spectrom. 2009, 15, 113-130. 